\title{
Spectral Characteristics of Randomly Switched PWM DC/DC Converters Operating in Discontinuous Conduction Mode
}

\author{
K. K. Tse, Member, IEEE, Henry Shu-hung Chung, Member, IEEE, S. Y. R. Hui, Senior Member, IEEE, and \\ H. C. So, Member, IEEE
}

\begin{abstract}
This paper addresses a comparative study of the spectral characteristics of four random-switching schemes that apply to the basic pulsewidth-modulation (PWM) dc/dc converters operating in discontinuous conduction mode (DCM). They include randomized pulse position modulation, randomized pulsewidth modulation, and randomized carrier frequency modulation with fixed duty cycle and with fixed duty time, respectively. Mathematical models that characterize the input current and output voltage of the three basic PWM converters operating in DCM are derived. In particular, the effectiveness of spreading the dominant switching harmonics in the input current that normally exist in the standard PWM scheme and the introduction of low-frequency harmonics in the output voltage with respect to the randomness level are investigated. The validity of the models and analyses are confirmed experimentally by using a dc/dc buck converter.
\end{abstract}

Index Terms-DC-DC power conversion, power electronics, pulsewidth modulation, random-switching techniques, switching circuits.

\section{INTRODUCTION}

$\mathbf{N}$ OWADAYS, switching converters have to be designed not only to meet electrical specifications, but also to comply with the international electromagnetic compatibility (EMC) standards. With the introduction of the EMC directive, there is an increasing awareness of EMC issues that highlights the electromagnetic interference (EMI) problem of switching converters [1], [2]. The pulsewidth-modulation (PWM) scheme is a common technique that controls the power flow of switching converters. The switching frequency is fixed and the duty cycle of the semiconductor switches is the control parameter. Under the steady-state operation, both the duty cycle and the switching frequency of the gate signals are kept constant. The harmonic powers of the input current and the output voltage concentrate on the multiples of the switching frequency. During the last decade, random switching, which is originated from statistical communication theory [3], has been applied to switching converters. Certain parameters, namely, random (stochastic) variables, in the PWM modulator are subject to randomization. The methodology is not merely a way to comply with the EMC regulations, but also provides a flexible and practical approach

Manuscript received June 9, 1999; revised February 3, 2000. Abstract published on the Internet April 21, 2000.

The authors are with the Department of Electronic Engineering, City University of Hong Kong, Kowloon, Hong Kong.

Publisher Item Identifier S 0278-0046(00)06831-3. to solving acoustic noise problems in inverter-based motor drive [4].

In this paper, the use of random-switching schemes for basic PWM dc/dc converters operating in discontinuous conduction mode (DCM) is presented. Under DCM, the energy stored in the inductor is completely transferred to the output load in every switching cycle. This feature inherently improves the converter stability and offers the advantage of stable closed-loop operation [5]. However, the pulsating input current waveform consists of the harmonics at the multiples of the switching frequency, which are the major sources of conducted EMI [6]. With random-switching schemes, the harmonic power concentration along the frequency spectrum will be relaxed, and the peak level of the power spectral density (PSD) becomes less than that of classical PWM. Discrete harmonics are significantly reduced and the harmonic power is spread over as continuous noise spectrum of insignificant magnitude. There are many randomization schemes, which can spread the harmonic energy present at one frequency across other frequencies. Their syntheses have been addressed in many papers [7]-[9]. Based on the standard PWM scheme, four modulation schemes can be categorized. They include random-pulse-position modulation (RPPM), random-pulsewidth modulation (RPWM), and random-carrier-frequency modulation with fixed duty cycle (RCFMFD) and with variable duty cycle (RCFMVD), respectively. It has been shown in [11] that, among the four schemes, RCFMFD introduces the lowest low-frequency output noise voltage within the passband of the low-pass filter in $\mathrm{dc} / \mathrm{dc}$ converters operating in continuous conduction mode (CCM). It is, therefore, the best choice for application to converters that require tight output voltage regulation. However, the suitability and applicability of the use of random modulation schemes for converters operating in DCM have not been addressed.

A comparative study of the spectral characteristics of the four random-switching schemes that apply to the PWM dc/dc converters operating in DCM will be presented in this paper. Mathematical models that characterize the input current and output voltage of the three basic PWM converters, including buck, boost, and buck-boost converters, operating in DCM are derived. The methodology starts with the derivations of the spectral characteristics of a generalized current waveform under different random switching schemes and an equivalent transimpedance network for the three basic dc/dc converters. Investigation emphases include the effectiveness of spreading the dominant switching harmonics in the input current that 


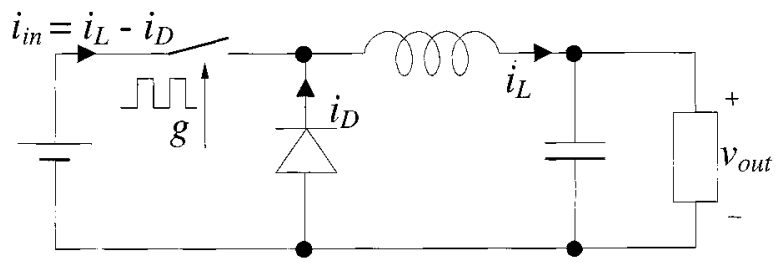

(a)

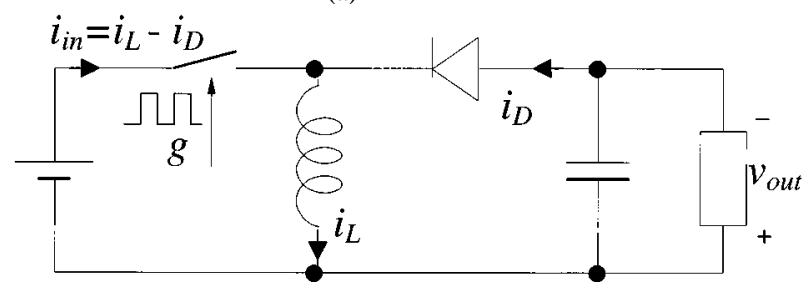

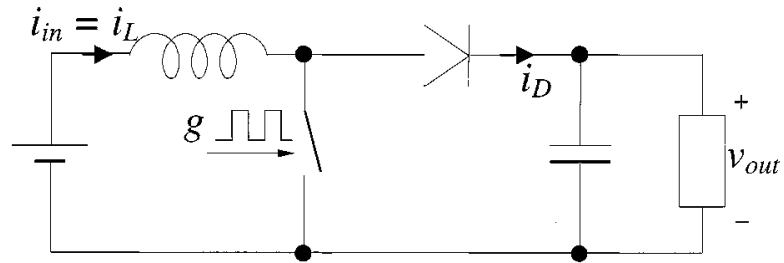

(b)

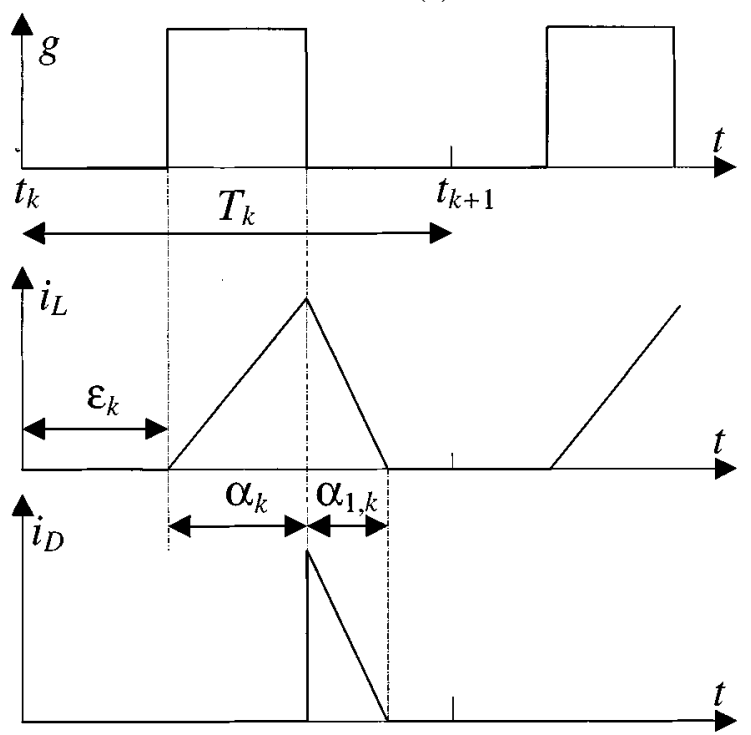

(d)

(c)

Fig. 1. Three PWM dc/dc converters. (a) Buck converter. (b) Boost converter. (c) Buck-boost converter. (d) Theoretical waveforms of $g, i_{L}$, and $i_{D}$.

normally exist in standard PWM scheme and the degree of low-frequency harmonics introduced in the output voltage with respect to the randomness level. They are quantitatively studied with uniform probability density distribution on the stochastic variables. The validity of the models and analyses are confirmed experimentally by using a dc/dc buck converter.

\section{RANDOM SWITCHING SCHEMES}

Fig. 1(a)-(c) shows the circuit diagrams of the three basic PWM converters. The gate signal $g$, inductor current $i_{L}$, and the diode current $i_{D}$ in a generic switching cycle $k$ are illustrated in Fig. 1(d). Under DCM, all current waveforms can be represented by triangular pulses and expressed in a general form of

$$
i(t)=\sum_{k=0}^{\infty} i_{k}\left(t-t_{k}\right)
$$

in which

$$
i_{k}\left(t-t_{k}\right)=\left\{\begin{array}{l}
A \times\left(t-t_{k}-\varepsilon_{k}\right) \\
\quad \text { for } \varepsilon_{k} \leq t-t_{k} \leq \varepsilon_{k}+\alpha_{k} \\
I_{k}-B \times\left(t-t_{k}-\varepsilon_{k}-\alpha_{k}\right) \\
\quad \text { for } \varepsilon_{k}+\alpha_{k} \leq t-t_{k} \leq \varepsilon_{k}+\alpha_{k}+\alpha_{1, k} \\
0, \quad \text { elsewhere }
\end{array}\right.
$$

where

$t_{k} \quad$ time at which the $k$ th switching cycle starts;

$\alpha_{k} \quad$ duration of the rising slope;

$\alpha_{1, k} \quad$ duration of the falling slope;

$\varepsilon_{k} \quad \quad$ delay time of the pulse;
$A, B$ slopes of the rising edge and the falling edge, respectively.

$I_{k}$ is the initial value of the pulse at $\varepsilon_{k}+\alpha_{k} \leq t-t_{k} \leq$ $\varepsilon_{k}+\alpha_{k}+\alpha_{1, k}$ and can be related to $\alpha_{k}$ in the form of

$$
I_{k}=F \alpha_{k}
$$

where $F$ is a constant. In addition, $\alpha_{1, k}$ can be related to $\alpha_{k}$ by

$$
\alpha_{1, k}=H \alpha_{k}
$$

where $H$ is a constant. Moreover, the duty cycle $D_{k}$ of $g$ in Fig. 1(d) in the $k$ th cycle is defined as

$$
D_{k}=\frac{\alpha_{k}}{T_{k}}
$$

where $T_{k}$ is the switching period of the $k$ th cycle.

The above equations form the basis for the derivations of the input current $i_{\text {in }}$ and the output voltage $v_{\text {out }}$ of the three converters. $i_{\text {in }}$ can be expressed in the form of (2)-(4). The values of $A, B, F$, and $H$ are tabulated in Table $\mathrm{I}(\mathrm{a})$. Moreover, as shown in Fig. 2, an equivalent circuit can be used to represent the output stage of the three converters. It consists of a current source $I_{S}$, an output capacitor $C$, and an output load $R$. $C$ and $R$ form a transimpedance $Z_{T}$, which is defined as the ratio between the spectral magnitude of the output voltage $v_{\text {out }}(f)$ and current source $I_{S}(f)$

$$
Z_{T}(f)=\frac{v_{\text {out }}(f)}{I_{S}(f)}=\frac{R}{1+j 2 \pi f C R} .
$$




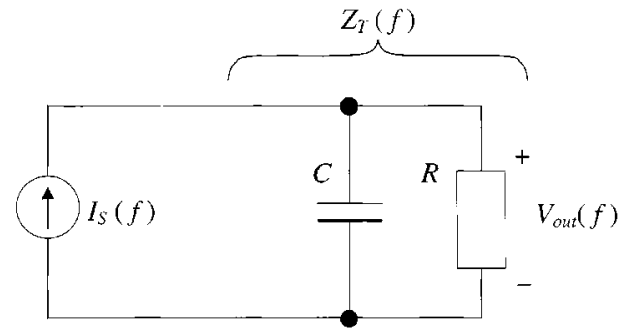

Fig. 2. Equivalent circuit of the output stage of the three converters.

TABLE I

(a) VAlues of $A, B, F$, AND $H$ FOR $i_{\text {in }}$ IN THE THREe DC/DC CONVERTERS (b) VALUES OF $A, B, F$, AND $H$ FOR $i_{S}$ IN THE THREE DC/DC CONVERTERS

\begin{tabular}{c|c|c|c|c}
\hline $\begin{array}{c}\text { Converter } \\
\text { Type }\end{array}$ & $A$ & $B$ & $F$ & $H$ \\
\hline Buck & $\frac{V_{\text {in }}-V_{\text {out }}}{L}$ & 0 & 0 & $\frac{V_{\text {in }}-V_{\text {out }}}{V_{\text {out }}}$ \\
\hline Boost & $\frac{V_{\text {in }}}{L}$ & $\frac{V_{\text {out }}-V_{\text {in }}}{L}$ & $\frac{V_{\text {in }}}{L}$ & $\frac{V_{\text {in }}}{V_{\text {out }}-V_{\text {in }}}$ \\
\hline $\begin{array}{c}\text { Buck- } \\
\text { boost }\end{array}$ & $\frac{V_{\text {in }}}{L}$ & 0 & 0 & $\frac{V_{\text {in }}}{V_{\text {out }}}$ \\
\hline
\end{tabular}

(a)

\begin{tabular}{c|c|c|c|c|c}
\hline $\begin{array}{c}\text { Converter } \\
\text { Type }\end{array}$ & $\begin{array}{c}\text { Source of } \\
i_{S}\end{array}$ & $A$ & $B$ & $F$ & $H$ \\
\hline Buck & $i_{L}$ & $\frac{V_{\text {in }}-V_{\text {out }}}{L}$ & $\frac{V_{\text {out }}}{L}$ & $\frac{V_{\text {in }}-V_{\text {out }}}{L}$ & $\frac{V_{\text {in }}-V_{\text {out }}}{V_{\text {out }}}$ \\
\hline Boost & $i_{D}$ & 0 & $\frac{V_{\text {out }}-V_{\text {in }}}{L}$ & $\frac{V_{\text {in }}}{L}$ & $\frac{V_{\text {in }}}{V_{\text {out }}-V_{\text {in }}}$ \\
\hline $\begin{array}{c}\text { Buck- } \\
\text { boost }\end{array}$ & $i_{D}$ & 0 & $\frac{V_{\text {out }}}{L}$ & $\frac{V_{\text {in }}}{L}$ & $\frac{V_{\text {in }}}{V_{\text {out }}}$ \\
\hline
\end{tabular}

(b)

Depending on the converter, $I_{S}$ can be $i_{L}$ or $i_{D}$ and is defined in Table $\mathrm{I}(\mathrm{b})$, together with the values of $A, B, F$, and $H$. In Table I, $V_{\text {in }}$ and $V_{\text {out }}$ are the nominal values of the input and output voltages, respectively. The values of $V_{\text {out }}$ for the three converters are tabulated in Table II [5].

\section{A. Characteristics of Different Random Modulation Schemes}

As shown in Fig. 1(d) $i_{L}$ and $i_{D}$ under different random switching schemes are subject to randomization of $\varepsilon_{k}, \alpha_{k}$ or $T_{k}$, which can be considered as stochastic variables. RPPM is similar to the classical PWM scheme with constant-switching frequency. However, the pulse position is randomized within each switching period, instead of commencing at the start of each cycle. The delay time $\varepsilon_{k}$ controls the randomness level in RPPM scheme. For RPWM, each pulse starts without time delay (i.e., $\varepsilon_{k}=0$ ), but $\alpha_{k}$ is randomized. The average value of $\alpha_{k}$ over the switching period is equal to the nominal duty cycle. RCFMFD exhibits randomized switching period $T_{k}$ and constant duty cycle, while RCFMVD exhibits randomized switching period $T_{k}$ and constant pulse duration. Characteristics of the stochastic variables in the four random switching schemes are summarized in Table III.
TABLE II

$V_{\text {out }}$ OF THE THREE DC/DC CONVERTERS [5]

\begin{tabular}{l|c|l}
\hline $\begin{array}{c}\text { Converter } \\
\text { Type }\end{array}$ & \multicolumn{1}{|c|}{$V_{\text {out }}$} & In which \\
\hline Buck & $\frac{1}{2}\left(\sqrt{\left(\frac{K}{V_{\text {in }}}\right)^{2}+4 K}-\frac{K}{V_{\text {in }}}\right)$ & \multirow{2}{*}{$K=\frac{\left(D V_{\text {in }}\right)^{2} R T}{2 L}$} \\
\hline Boost & $\frac{1}{2}\left(V_{\text {in }}+\sqrt{V_{\text {in }}{ }^{2}+4 K}\right)$ & \\
\hline Buck-boost & $\sqrt{K}$ & \\
\hline
\end{tabular}

TABLE III

CHARACTERISTICS OF STOCHASTIC VARIABLES IN THE FOUR RANDOM SWITCHING SCHEMES

\begin{tabular}{c|c|c|c|c}
\hline Switching schemes & $T_{k}$ & $\alpha_{k}$ & $\varepsilon_{k}$ & $D_{k}=\alpha_{k} / T_{k}$ \\
\hline Standard PWM & Fixed & Fixed & Zero & Fixed \\
\hline RPPM & Fixed & Fixed & Randomized & Fixed \\
\hline RPWM & Fixed & Randomized & Zero & Randomized \\
\hline RCFMFD & Randomized & Randomized & Zero & Fixed \\
\hline RCFMVD & Randomized & Fixed & Zero & Randomized \\
\hline
\end{tabular}

\section{B. Definitions of the Randomness Level}

Randomness level $\Re$ for each scheme is defined as follows. For RPPM,

$$
\Re_{\mathrm{RPPM}}=\frac{\varepsilon_{u}-\varepsilon_{l}}{T}
$$

where the delay time $\varepsilon_{k} \in\left[\varepsilon_{l}, \varepsilon_{u}\right] . \varepsilon_{l}$ and $\varepsilon_{u}$ are the lower and upper limits of the pulse delay time in each cycle. $\varepsilon_{l}$ is generally equal to zero. $T$ is the nominal switching period.

For RPWM,

$$
\Re_{\mathrm{RPWM}}=\frac{\alpha_{u}-\alpha_{l}}{T}=D_{u}-D_{l}
$$

where the pulse on-time $\alpha_{k} \in\left[\alpha_{l}, \alpha_{u}\right]$. Thus, the duty cycle $D_{k}$ varies between the minimum possible value $D_{l}$ and the maximum possible value $D_{u}$ around the nominal duty cycle.

For RCFMFD and RCFMVD,

$$
\Re_{\mathrm{RCFMFD}}=\Re_{\mathrm{RCFMVD}}=\frac{T_{u}-T_{l}}{T} .
$$

$T_{k}$ varies between a maximum possible value $T_{u}$ and a minimum value $T_{l}$.

\section{Power Spectral Density of $i_{\mathrm{in}}$ and $i_{S}$}

For RPPM and RPWM, it has been shown in [11] that the PSD of the current waveform $S_{p}(f, \Re)$ in Fig. 1(d) can be expressed as follows:

$$
\begin{aligned}
S_{p}(f, \Re)=f_{S}\{ & E\left[|I(f)|^{2}\right]-|E[I(f)]|^{2} \\
& \left.+f_{S}|E[I(f)]|^{2} \sum_{k=-\infty}^{\infty} \delta\left(f-k f_{S}\right)\right\}
\end{aligned}
$$

where $f_{S}$ is the nominal switching frequency and $I(f)$ is the Fourier transform of a cycle of $i(t)$. $E[\cdot]$ is the expectation operator taking over the whole ensemble with randomness level $\Re$. The expectation terms in (10) are derived as follows. 
For RPPM, the pulsewidth is fixed at $\alpha$. Therefore,

$$
\begin{aligned}
I(f)= & \int_{\varepsilon_{k}}^{\alpha+\varepsilon_{k}} A\left(t-\varepsilon_{k}\right) e^{-j 2 \pi f t} d t \\
& +\int_{\alpha+\varepsilon_{k}}^{\alpha_{1}+\alpha+\varepsilon_{k}}\left[F \alpha-B\left(t-\alpha-\varepsilon_{k}\right)\right] e^{-j 2 \pi f t} d t \\
= & \frac{e^{-j 2 \pi f \varepsilon_{k}}}{(2 \pi f)^{2}}\left\{[A+B+j 2 \pi f \alpha(A-F)] e^{-j 2 \pi f \alpha}\right. \\
& \left.-[B-j 2 \pi f \alpha(F-B H)] e^{-j 2 \pi f(1+H) \alpha}-A\right\} .
\end{aligned}
$$

If $\varepsilon_{k}$ is randomized with the probability density function $P\left(\varepsilon_{k}\right)$ and within the range between $\varepsilon_{u}$ and $\varepsilon_{l}$, the expected values of $I(f)$ and $|I(f)|^{2}$ equal

$$
\begin{aligned}
E[I(f)] & =\int_{\varepsilon_{l}}^{\varepsilon_{u}} P\left(\varepsilon_{k}\right) I(f) d \varepsilon_{k} ; \\
E\left[|I(f)|^{2}\right] & =\int_{\varepsilon_{l}}^{\varepsilon_{u}} P\left(\varepsilon_{k}\right) I(f) I^{*}(f) d \varepsilon_{k}
\end{aligned}
$$

where $I^{*}(f)$ is the complex conjugate of $I(f)$. If $P\left(\varepsilon_{k}\right)$ is of uniform distribution,

$$
P\left(\varepsilon_{k}\right)= \begin{cases}\frac{1}{\varepsilon_{u}-\varepsilon_{l}}=\frac{1}{\Re_{\mathrm{RPPM}} T}, & \varepsilon_{l} \leq \varepsilon_{k} \leq \varepsilon_{u} \\ 0, & \text { otherwise }\end{cases}
$$

Hence,

$$
E[I(f)]=\frac{\Phi}{2 \pi f \Re_{\mathrm{RPPM}} T}\left(e^{-j 2 \pi f \varepsilon_{l}}-e^{-j 2 \pi f \varepsilon_{u}}\right)
$$

where

$$
\begin{aligned}
\Phi= & \frac{1}{(2 \pi f)^{2}}\left\{[A+B+j 2 \pi f \alpha(A-F)] e^{-j 2 \pi f \alpha}\right. \\
& \left.-[B-j 2 \pi f \alpha(F-B H)] e^{-j 2 \pi f(1+H) \alpha}-A\right\} .
\end{aligned}
$$

$\varepsilon_{k}$ can be eliminated in the absolute-squared value of (11). Thus,

$$
E\left[|I(f)|^{2}\right]=|I(f)|^{2} .
$$

For RPWM,

$$
\begin{aligned}
I(f)= & \int_{0}^{D_{k} T} A t e^{-j 2 \pi f t} d t \\
& +\int_{D_{k} T}^{(1+H) D_{k} T}\left[F D_{k} T-B\left(t-D_{k} T\right)\right] e^{-j 2 \pi f t} d t \\
= & \frac{1}{(2 \pi f)^{2}}\left\{\left[A+B+j 2 \pi f D_{k} T(A-F)\right] e^{-j 2 \pi f D_{k} T}\right. \\
& \left.-\left[B-j 2 \pi f D_{k} T(F-B H)\right] e^{-j 2 \pi f(1+H) D_{k} T}-A\right\} .
\end{aligned}
$$

If $D_{k}$ is uniformly distributed between $D_{u}$ and $D_{l}$,

$$
P\left(D_{k}\right)= \begin{cases}\frac{1}{D_{u}-D_{l}}=\frac{1}{\Re_{\mathrm{RPWM}}}, & D_{l} \leq D_{k} \leq D_{u} \\ 0, & \text { otherwise }\end{cases}
$$

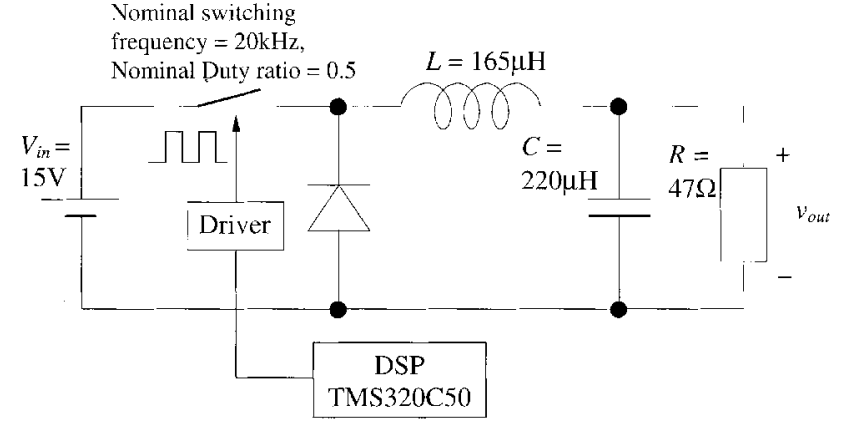

Fig. 3. Buck converter with the test setup.

Hence,

$$
\begin{aligned}
E[I(f)] & \int_{D_{l}}^{D_{u}} P\left(D_{k}\right) I(f) d D_{k} \\
= & \frac{j}{(2 \pi f)^{2} \Re_{\mathrm{RPWM}}} \\
& \cdot\left\{(A+B)\left(e^{-j 2 \pi f D_{u} T}-e^{-j 2 \pi f D_{l} T}\right)\right. \\
& -\frac{B}{1+H}\left(e^{-j 2 \pi f(1+H) D_{u} T}-e^{-j 2 \pi f(1+H) D_{l} T}\right) \\
& +(A-C)\left[\left(1+j 2 \pi f D_{u} T\right) e^{-j 2 \pi f D_{u} T}\right. \\
& \left.-\left(1+j 2 \pi f D_{l} T\right) e^{-j 2 \pi f D_{l} T}\right] \\
& +j A 2 \pi f T \Re_{\mathrm{RPWM}}+\frac{(F-B H)}{(1+H)^{2}} \\
& \cdot\left[\left(1+j 2 \pi f(1+H) D_{u} T\right) e^{-j 2 \pi f(1+H) D_{u} T}\right. \\
& \left.-\left(1+j 2 \pi(1+H) f D_{l} T\right) e^{\left.-j 2 \pi f(1+H) D_{l} T\right]}\right\} \\
E[\mid & \left.\left.I(f)\right|^{2}\right] \\
= & \int_{D_{l}}^{D_{u}} P\left(D_{k}\right) I(f) I^{*}(f) d D_{k} \\
= & \frac{2}{(2 \pi f)^{5} T \Re_{\mathrm{RPWM}}} \\
& \cdot\left\{\left[A^{2}+B^{2}+(A+B)^{2}\right] \pi f T \Re_{\mathrm{RPWM}}\right. \\
& +\frac{4}{3}\left[(F-B H)^{2}+(A-F)^{2}\right](\pi f T)^{3} \\
& \cdot\left(D_{u}^{3}-D_{l}^{3}\right)+\frac{(A+B)(F-B H)+(A-F) B}{H 2} \\
& \cdot\left[\sin \left(2 \pi f H T D_{u}\right)-\sin \left(2 \pi f H T D_{l}\right)-2 \pi f H T\right. \\
& \left.\cdot\left[D_{u} \cos \left(2 \pi f H T D_{u}\right)-D_{l} \cos \left(2 \pi f H T D_{l}\right)\right]\right] \\
& -\frac{A(F-B H)}{(1+H)^{2}}\left[\sin \left(2 \pi f(1+H) T D_{u}\right)\right. \\
& -\sin \left(2 \pi f(1+H) T D_{l}\right)-2 \pi f(1+H) T \\
& \cdot\left[D_{u} \cos \left(2 \pi f(1+H) T D_{u}\right)-D_{l}\right. \\
& \left.\left.\cdot \cos \left(2 \pi f(1+H) T D_{l}\right)\right]\right] \\
& -A(A+B)\left[\sin \left(2 \pi f T D_{u}\right)-\sin \left(2 \pi f T D_{l}\right)\right] \\
& \left.-\frac{B}{}(A+B)\left(2 \pi f H T D_{u}\right)-\sin \left(2 \pi f H T D_{l}\right)\right]
\end{aligned}
$$




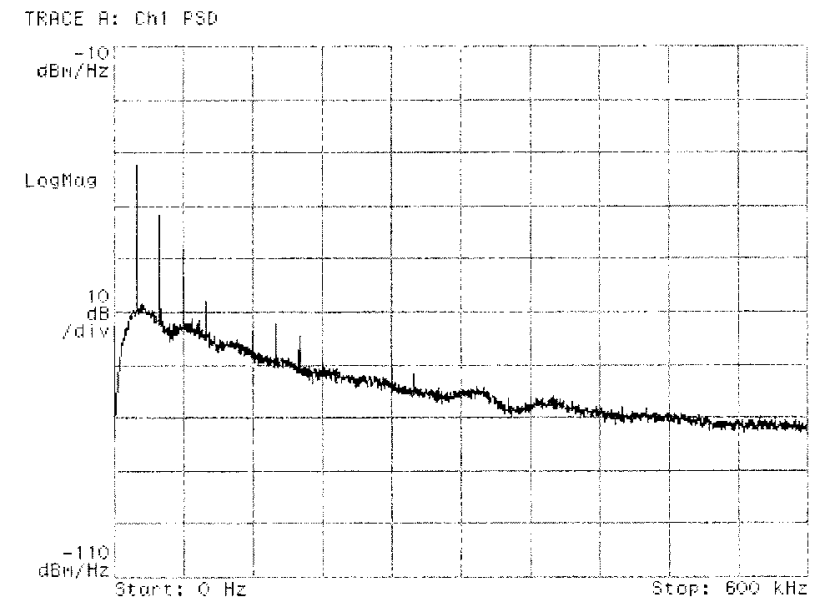

(a)

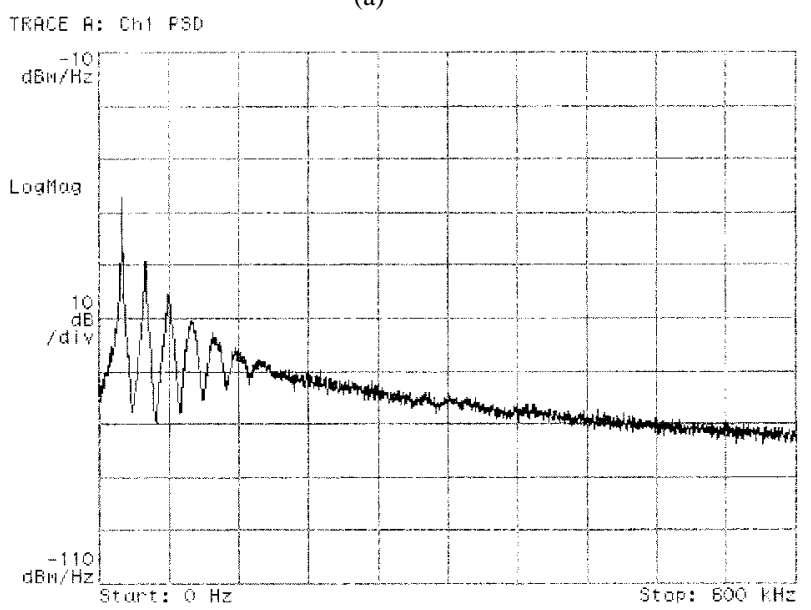

(c)

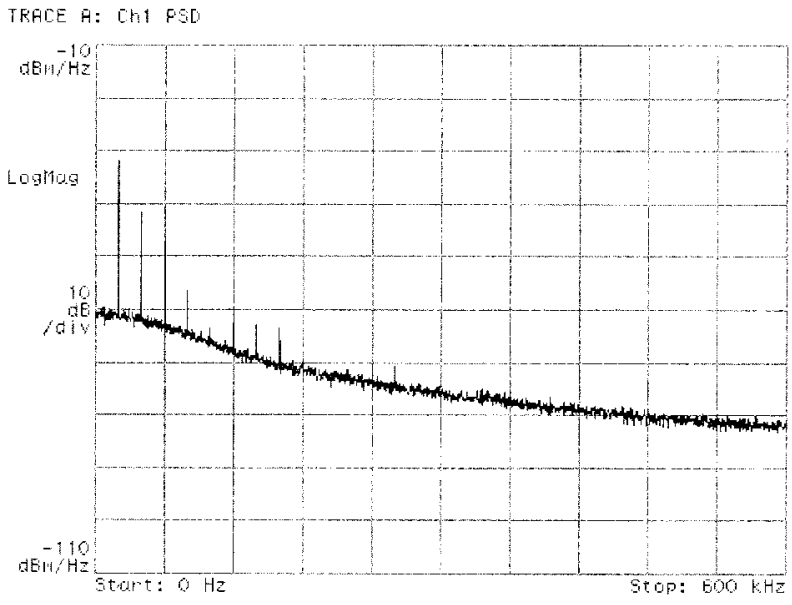

(b)

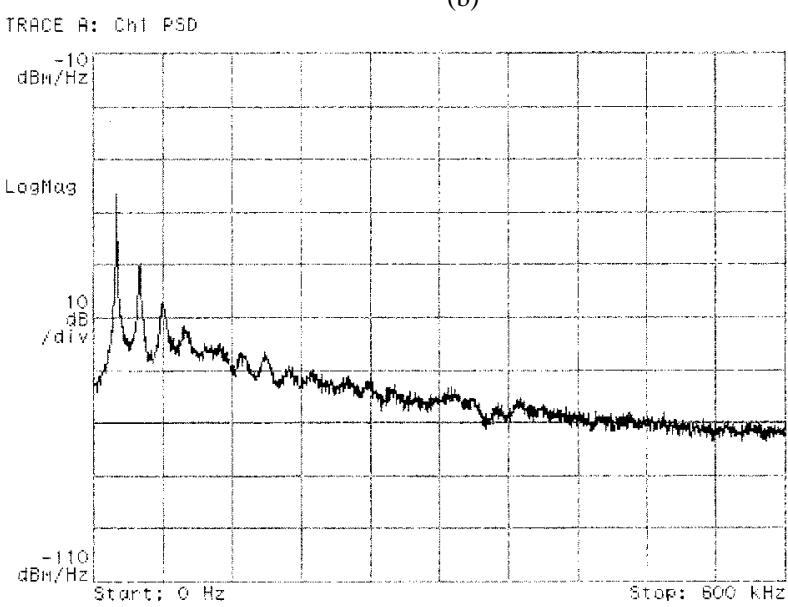

(d)

Fig. 4. Experimental results of the PSD of $i_{\text {in }}$ under the four schemes with $\Re=0.2$. (a) RPPM. (b) RPWM. (c) RCFMFD. (d) RCFMVD.

$+\frac{A B}{1+H}\left[\sin \left(2 \pi f(1+H) T D_{u}\right)\right.$

$\left.-\sin \left(2 \pi f(1+H) T D_{l}\right)\right]-\frac{2(A-F)(F-B H)}{H^{3}}$

- $\left[\sin \left(2 \pi f H T D_{u}\right)-\sin \left(2 \pi f H T D_{l}\right)\right.$

$-2 \pi f H T\left(D_{u} \cos \left(2 \pi f H T D_{u}\right)-D_{l}\right.$

$\left.\cdot \cos \left(2 \pi f H T D_{l}\right)\right)-\frac{(2 \pi f H T)^{2}}{2}$

$\left.\left[D_{u}^{2} \sin \left(2 \pi f H T D_{u}\right)-D_{l}^{2} \sin \left(2 \pi f H T D_{l}\right)\right]\right]$

$-A(A-F)\left[\sin \left(2 \pi f T D_{u}\right)-\sin \left(2 \pi f T D_{l}\right)\right.$

$\left.\left.-2 \pi f T\left[D_{u} \cos \left(2 \pi f T D_{u}\right)-D_{l} \cos \left(2 \pi f T D_{l}\right)\right]\right]\right\}$.

(21)

For RCFMFD and RCFMVD, the PSD of the current has been shown in [11] that

$S_{p}\left(f, \Re_{\mathrm{RCFM}}\right)$

$$
\begin{aligned}
= & \frac{1}{E\left[T_{k}\right]} \\
& \cdot\left\{E\left[|I(f)|^{2}\right]+2 \operatorname{Re}\left[\frac{E\left[I(f) e^{j 2 \pi f T_{k}}\right] E\left[I^{*}(f)\right]}{1-E\left[e^{j 2 \pi f T_{k}}\right]}\right]\right\} .
\end{aligned}
$$

The expected terms in (22) are expressed as follows.

For RCFMFD,

$$
\begin{aligned}
I(f)= & \int_{0}^{D T_{k}} A t e^{-j 2 \pi f t} d t \\
& +\int_{D T_{k}}^{(1+H) D T_{k}}\left[F D T_{k}-B\left(t-D T_{k}\right)\right] e^{-j 2 \pi f t} d t \\
= & \frac{1}{(2 \pi f)^{2}}\left\{\left[A+B+j 2 \pi f D T_{k}(A-F)\right] e^{-j 2 \pi f D T_{k}}\right. \\
& \left.-\left[B-j 2 \pi f D T_{k}(F-B H)\right] e^{-j 2 \pi f(1+H) D T_{k}}-A\right\}
\end{aligned}
$$

where $D$ is constant duty cycle.

$$
\begin{aligned}
& E\left[|I(f)|^{2}\right] \\
&=\int_{T_{l}}^{T_{u}} P\left(T_{k}\right) I(f) I^{*}(f) d T_{k} \\
&=\frac{2}{(2 \pi f)^{5} D \Re_{\mathrm{RCFMFD}} T} \\
&\left\{\left[A^{2}+B^{2}+(A+B)^{2}\right] \pi f D \Re_{\mathrm{RCFMFD}} T\right. \\
&+\frac{4}{3}\left[(F-B H)^{2}+(A-F)^{2}\right](\pi f D)^{3}\left(T_{u}^{3}-T_{l}^{3}\right)
\end{aligned}
$$




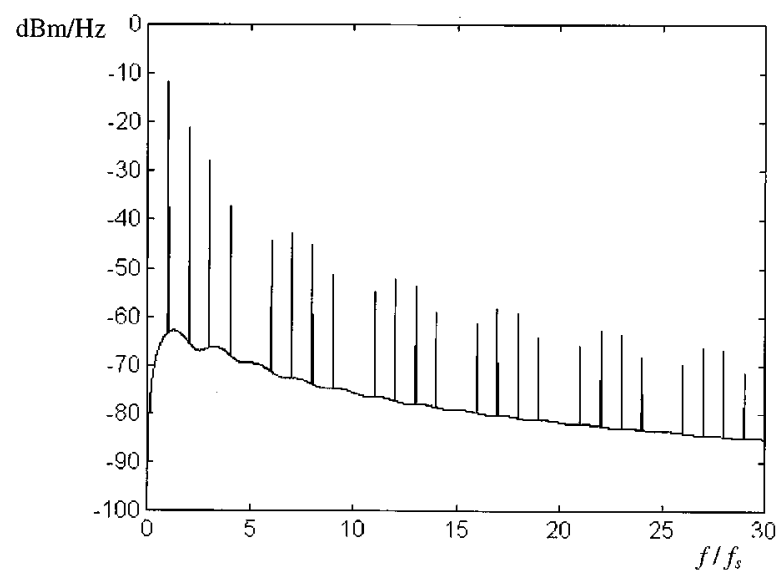

(a)

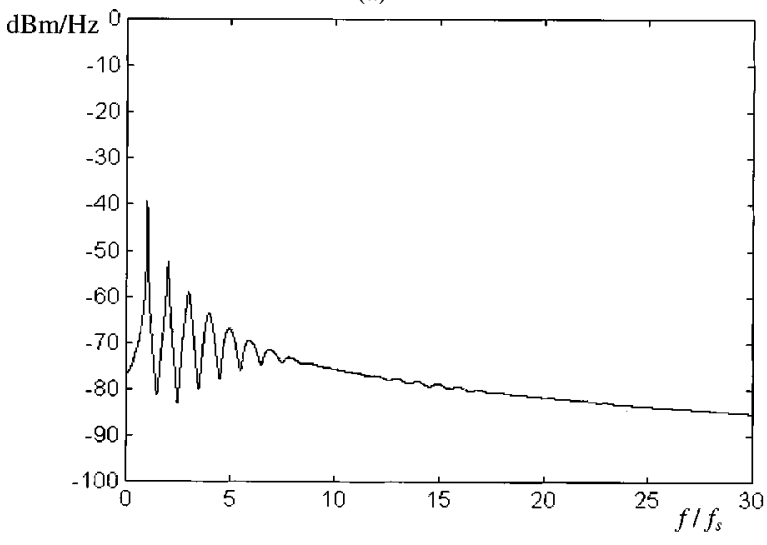

(c)

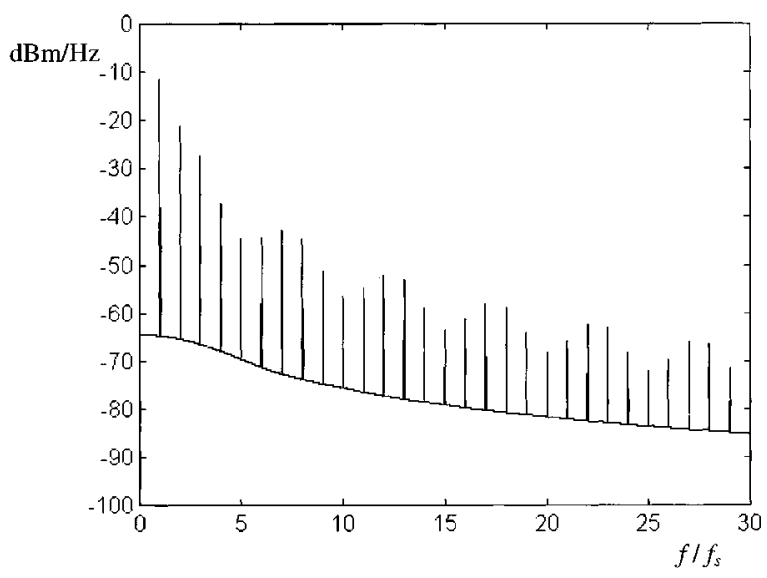

(b)

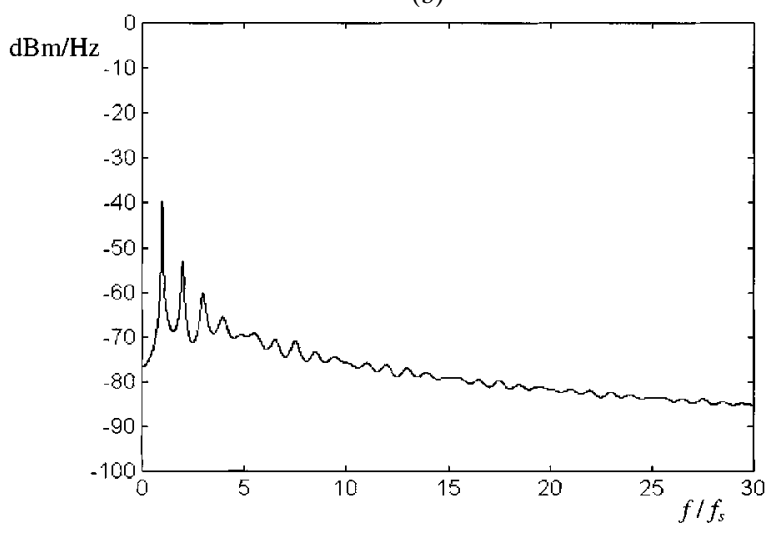

(d)

Fig. 5. Theoretical results of the PSD of $i_{\text {in }}$ under the four schemes with $\Re=0.2$. (a) RPPM. (b) RPWM. (c) RCFMFD. (d) RCFMVD.

$+\frac{(A+B)(F-B H)+(A-F) B}{H^{2}}$

- $\left[\sin \left(2 \pi f H D T_{u}\right)-\sin \left(2 \pi f H D T_{l}\right)-2 \pi f H D\right.$

- $\left.\left[T_{u} \cos \left(2 \pi f H D T_{u}\right)-T_{l} \cos \left(2 \pi f H D T_{l}\right)\right]\right]$

$-\frac{A(F-B H)}{(1+H)^{2}}\left[\sin \left(2 \pi f(1+H) D T_{u}\right)\right.$

$-\sin \left(2 \pi f(1+H) D T_{l}\right)-2 \pi f(1+H) D$

- $\left[T_{u} \cos \left(2 \pi f(1+H) D T_{u}\right)-T_{l}\right.$

$\left.\left.\cdot \cos \left(2 \pi f(1+H) D T_{l}\right)\right]\right]-A(A+B)$

$\cdot\left[\sin \left(2 \pi f D T_{u}\right)-\sin \left(2 \pi f D T_{l}\right)\right]-\frac{B(A+B)}{H}$

- $\left[\sin \left(2 \pi f H D T_{u}\right)-\sin \left(2 \pi f H D T_{l}\right)\right]+\frac{A B}{1+H}$

- $\left[\sin \left(2 \pi f(1+H) D T_{u}\right)-\sin \left(2 \pi f(1+H) D T_{l}\right)\right]$

$-\frac{2(A-F)(F-B H)}{H^{3}}\left[\sin \left(2 \pi f H D T_{u}\right)\right.$

$-\sin \left(2 \pi f H D T_{l}\right)-2 \pi f H D\left(T_{u} \cos \left(2 \pi f H D T_{u}\right)\right.$

$\left.-T_{l} \cos \left(2 \pi f H D T_{l}\right)\right)-\frac{(2 \pi f H D)^{2}}{2}$

- $\left.\left[T_{u}^{2} \sin \left(2 \pi f H D T_{u}\right)-T_{l}^{2} \sin \left(2 \pi f H D T_{l}\right)\right]\right]$

- $A(A-F)\left[\sin \left(2 \pi f D T_{u}\right)-\sin \left(2 \pi f D T_{l}\right)-2 \pi f D\right.$

- $\left.\left.\left[T_{u} \cos \left(2 \pi f D T_{u}\right)-T_{l} \cos \left(2 \pi f D T_{l}\right)\right]\right]\right\}$.

$$
\begin{aligned}
& E\left[I(f) e^{j 2 \pi f T_{k}}\right] \\
& =\int_{T_{l}}^{T_{u}} P\left(T_{k}\right) I(f) e^{j 2 \pi f T_{k}} d T_{k} \\
& =\frac{1}{j(2 \pi f)^{3 \Re_{\mathrm{RCFMFD}} T}} \\
& \cdot\left\{\frac{A+B}{1-D}\left(e^{j 2 \pi f(1-D) T_{u}}-e^{j 2 \pi f(1-D) T_{l}}\right)\right. \\
& -\frac{(A-F) D}{(1-D)^{2}}\left[\left(1-j 2 \pi f(1-D) T_{u}\right) e^{j 2 \pi f(1-D) T_{u}}\right. \\
& \left.-\left(1-j 2 \pi f(1-D) T_{l}\right) e^{j 2 \pi f(1-D) T_{l}}\right] \\
& -\frac{(F-B H) D}{(1-D-H D)^{2}}\left[\left(1-j 2 \pi f(1-D-H D) T_{u}\right)\right. \\
& \cdot e^{j 2 \pi f(1-D-H D) T_{u}}-\left(1-j 2 \pi f(1-D-H D) T_{l}\right) \\
& \left.\cdot e^{j 2 \pi f(1-D-H D) T_{l}}\right]-\frac{B}{1-D-H D} \\
& \cdot\left(e^{j 2 \pi f(1-D-H D) T_{u}}-e^{j 2 \pi f(1-D-H D) T_{l}}\right) \\
& \left.-A\left(e^{j 2 \pi f T_{u}}-e^{j 2 \pi f T_{l}}\right)\right\} . \\
& E\left[I^{*}(f)\right] \\
& =\int_{T_{l}}^{T_{u}} P\left(T_{k}\right) I^{*}(f) d T_{k}
\end{aligned}
$$




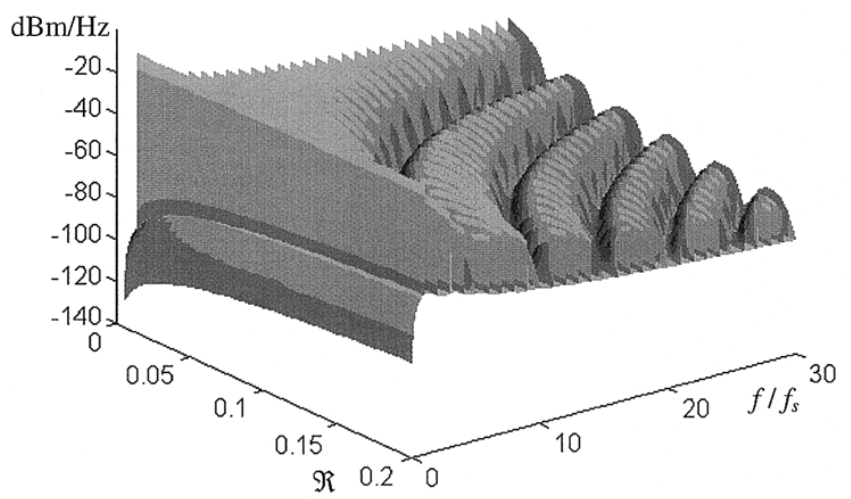

(a)

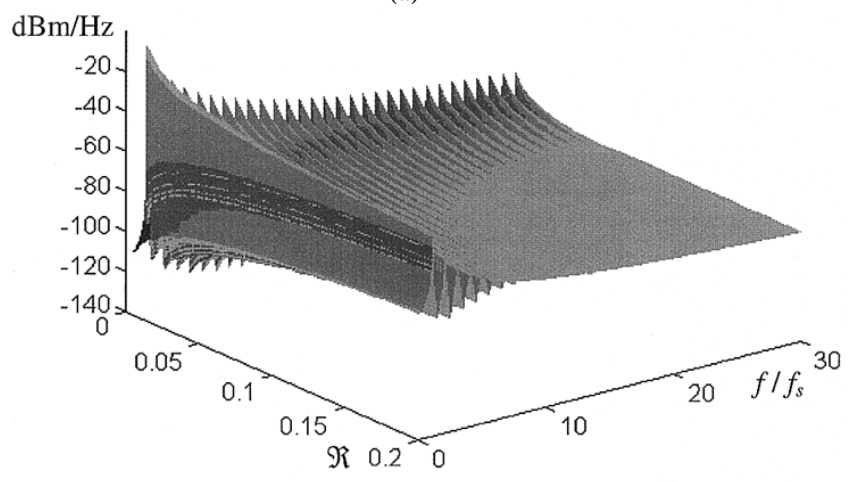

(c)

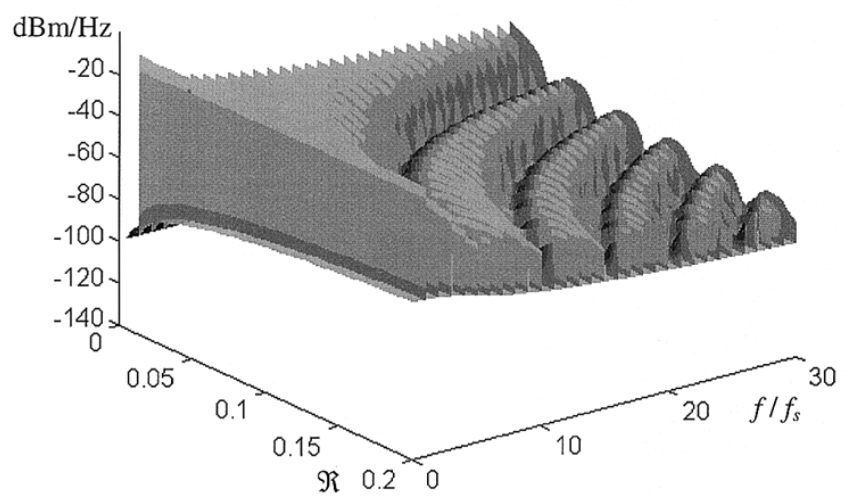

(b)

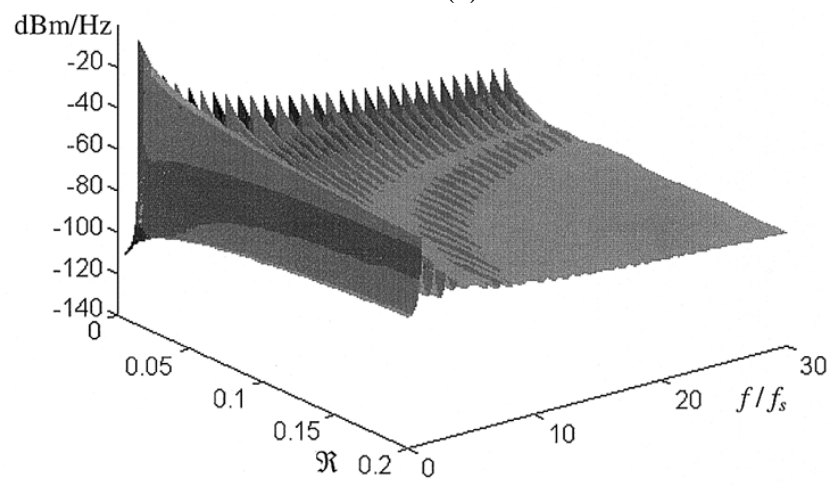

(d)

Fig. 6. Theoretical results of the PSD of $i_{\text {in }}$ with respect to the changes in $\Re$ from 0 to 0.2. (a) RPPM. (b) RPWM. (c) RCFMFD. (d) RCFMVD.

$$
\begin{aligned}
= & \frac{1}{j(2 \pi f)^{3} D \Re_{\mathrm{RCFMFD}} T} \\
& \cdot\left\{(A+B)\left(e^{j 2 \pi f D T_{u}}-e^{j 2 \pi f D T_{l}}\right)+(A-F)\right. \\
& \cdot\left[\left(1-j 2 \pi f D T_{u}\right) e^{j 2 \pi f D T_{u}}-\left(1-j 2 \pi f D T_{l}\right) e^{j 2 \pi f D T_{l}}\right] \\
& +\frac{(F-B H)}{(1+H)}\left[\left(1-j 2 \pi f(1+H) D T_{u}\right) e^{j 2 \pi f(1+H) D T_{u}}\right. \\
& \left.-\left(1-j 2 \pi f(1+H) D T_{l}\right) e^{j 2 \pi f(1+H) D T_{l}}\right] \\
& -\frac{B}{(1+H)}\left(e^{j 2 \pi f(1+H) D T_{u}}-e^{j 2 \pi f(1+H) D T_{l}}\right) \\
& \left.-j 2 \pi f A \Re_{\mathrm{RCFMFD}} D T\right\} \cdot \\
E\left[e^{j 2 \pi f T_{k}}\right] & \int_{T_{1}}^{T_{2}} P\left(T_{k}\right) e^{j 2 \pi f T_{k}} d T_{k} \\
= & \frac{1}{j 2 \pi f \Re_{\mathrm{RCFMFD}} T}\left[e^{j 2 \pi f T_{u}}-e^{j 2 \pi f T_{l}}\right] .
\end{aligned}
$$

For RCFMVD,

$$
\begin{aligned}
I(f)= & \int_{0}^{\alpha} A t e^{-j 2 \pi f t} d t \\
& +\int_{\alpha}^{(1+H) \alpha}[F \alpha-B(t-\alpha)] e^{-j 2 \pi f t} d t \\
= & \frac{1}{(2 \pi f)^{2}}\left\{[A+B+j 2 \pi f \alpha(A-F)] e^{-j 2 \pi f \alpha}\right. \\
& \left.-[B-j 2 \pi f \alpha(F-B H)] e^{-j 2 \pi f(1+H) \alpha}-A\right\}
\end{aligned}
$$

$$
\begin{aligned}
E\left[|I(f)|^{2}\right] & =|I(f)|^{2} . \\
E\left[I(f) e^{j 2 \pi f T_{k}}\right] & =\frac{I(f)}{j 2 \pi f \Re_{\mathrm{RCFMVD}} T}\left(e^{j 2 \pi f T_{u}}-e^{j 2 \pi f T_{l}}\right) . \\
E\left[I^{*}(f)\right] & =I^{*}(f) . \\
E\left[e^{j 2 \pi f T_{k}}\right] & =\frac{1}{j 2 \pi f \Re_{\mathrm{RCFMVD}} T}\left(e^{j 2 \pi f T_{u}}-e^{j 2 \pi f T_{l}}\right) .
\end{aligned}
$$

The PSD's for RPPM and RPWM are determined by substituting (11)-(17) and (18)-(21) into (10), respectively. The PSD's for RCFMFD and RCFMVD are obtained by substituting (23)-(27), and (28)-(32) into (22), respectively. All calculations are based on the parameters in Table I(a) and (b). Hence, (10) and (22) are applicable for both $i_{\text {in }}$ and $i_{S}$.

\section{PSD of the Output Noise Ripple}

In Fig. 2, the equivalent source current $i_{S}$ flows into an $R-C$ transimpedance network to form the output voltage. The PSD of the noise output $S_{n_{o}}(f, \Re)$ of the converter can be obtained by multiplying the PSD of $i_{S}$, which is denoted by $S_{p}(f, \Re)$, with the absolute-squared value of the transimpedance [11]. That is,

$$
S_{n_{o}}(f, \Re)=S_{p}(f, \Re)\left|Z_{T}(f)\right|^{2}, \quad f \neq 0 .
$$

The noise power is calculated by integrating $S_{n_{o}}(f, \Re)$ over the spectrum. Hence, the root-mean-square value of low-frequency 


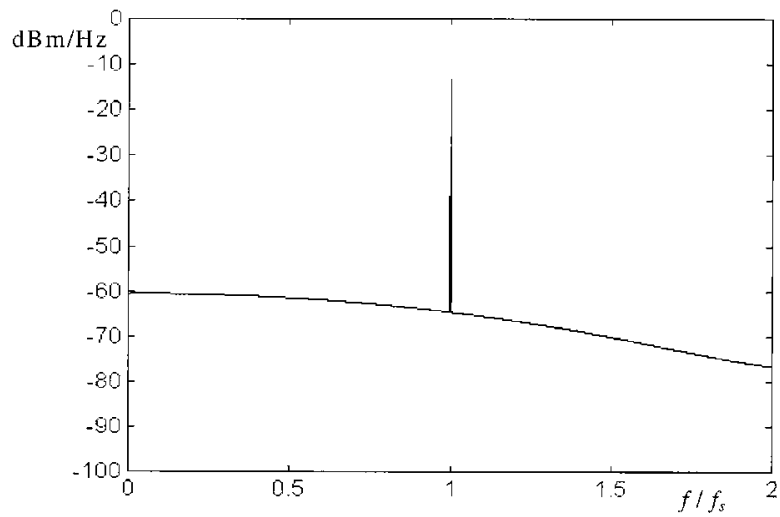

(a)

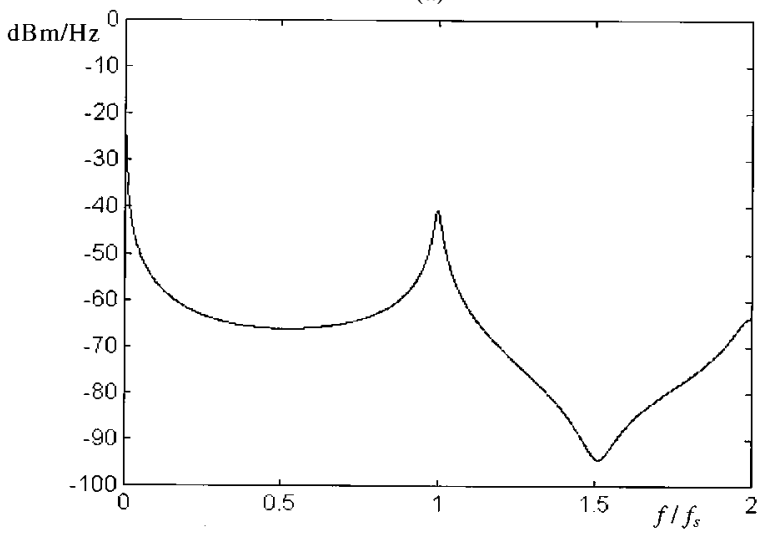

(c)

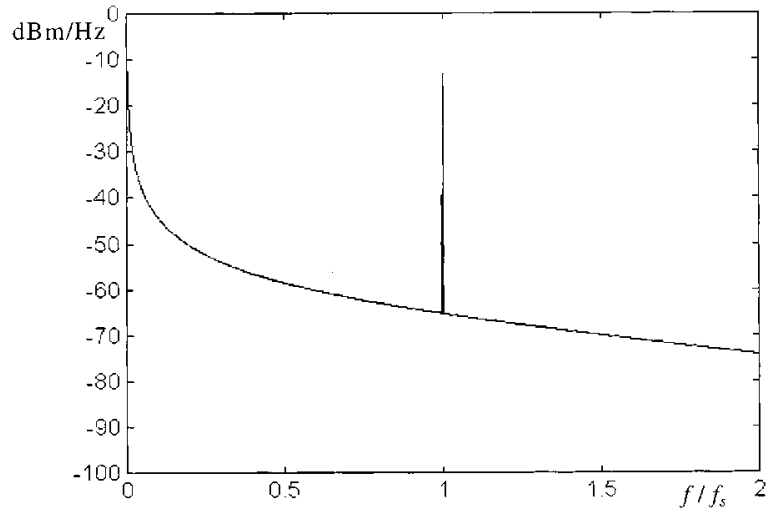

(b)

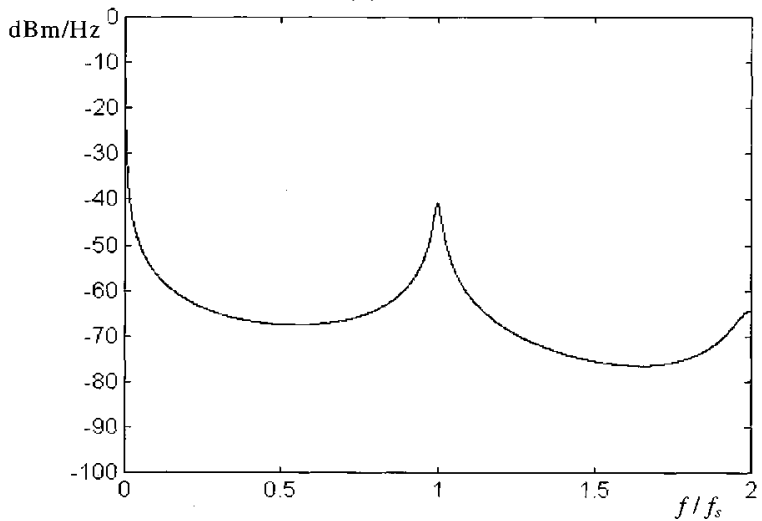

(d)

Fig. 7. Low-frequency characterizations of $v_{\text {out }}$ under the four random switching schemes. (a) RPPM. (b) RPWM. (c) RCFMFD. (d) RCFMVD.

noise ripple $v_{N}$ in the converter output can be approximated [10] by

$$
v_{N}(\Re)=\left[2 \int_{0}^{2 f_{s}} S_{p}(f, \Re)\left|Z_{T}(f)\right|^{2} d f\right]^{1 / 2}, \quad f \neq 0 .
$$

For RPPM and RPWM, $v_{N}$ can be determined numerically by the equation of

$$
\begin{aligned}
v_{N}=\left[\frac{4 f_{S}}{N} \sum_{k=1}^{N} S_{p}^{C}\left(\frac{2 k f_{S}}{N}, \Re\right)\left|Z_{T}\left(\frac{2 k f_{S}}{N}\right)\right|^{2}\right. \\
\left.+2 S_{p}^{D}\left(f_{S}, \Re\right)\left|Z_{T}\left(f_{S}\right)\right|^{2}\right]^{1 / 2}
\end{aligned}
$$

where $\left[S_{p}^{C}(f, \Re)\right]$ is the continuous spectral components in (10), $\left[S_{p}^{D}(f, \Re)\right]$ is the discrete spectral components in (10), and $N$ is the number of frequency points over the range of $\left[0,2 f_{s}\right]$.

For RCFMFD and RCFMVD,

$$
v_{N}=\left[\frac{4 f_{S}}{N} \sum_{k=1}^{N} S_{p}^{C}\left(\frac{2 k f_{S}}{N}, \Re\right)\left|Z_{T}\left(\frac{2 k f_{S}}{N}\right)\right|^{2}\right]^{1 / 2} \text {. }
$$

\section{EXPERIMENTAL VERIFICATIONS}

A dc/dc buck converter is illustrated with a test setup in Fig. 3. The component values are $L=165 \mu \mathrm{H}, C=220 \mu \mathrm{F}$, and $R=47 \Omega$. The input voltage $V_{\text {in }}$ is $15 \mathrm{~V}$. The nominal switching frequency $f_{S}$ is $20 \mathrm{kHz}$ and the duty cycle is 0.5 . The nominal output voltage is $11 \mathrm{~V}$. The synthesis of random switching pulses is accomplished by using a digital signal processor TMS320C50.

Figs. 4 and 5 show the experimental and the theore]tical results of the PSD of $i_{\text {in }}$ under the four schemes with randomness level $\Re=0.2$. The measurements are carried out with a signal analyzer HP89410A with resolution bandwidth of $100 \mathrm{~Hz}$. It is noted that the unit of the experimental results is in decibels per hertz, which is analyzed as a comparative result of the actual spectral power with respect to a reference of $1 \mathrm{~mW}$. Hence, for the sake of comparison between experimental results and theoretical ones, an offset of $30 \mathrm{~dB}$ is added to the theoretical solutions from (10) and (22). That is,

$$
\begin{aligned}
S_{\mathrm{dBm} / \mathrm{Hz}} & =10 \log \frac{S_{p}(f)}{0.001} \\
& =10 \log S_{p}(f)+30 \mathrm{~dB} \\
& =S_{\mathrm{dB} / \mathrm{Hz}}+30 \mathrm{~dB} .
\end{aligned}
$$

The theoretical predictions show close agreement with the experimental ones, except for the discrete harmonics in RPPM and RPWM. There is a 20-dB difference in the discrete harmonics. The reason is that, if a spectrum analyzer measures the PSD of $i_{\mathrm{in}}$, the measured PSD at frequency $f_{0}$ can be approximated by

$$
S_{p, \text { measured }}\left(f_{o}, \Re\right)=\frac{1}{B W_{\text {res }}} \int_{f_{o}-B W_{\text {res }} / 2}^{f_{o}+B W_{\text {res }} / 2} S_{p}(f, \Re) d f
$$




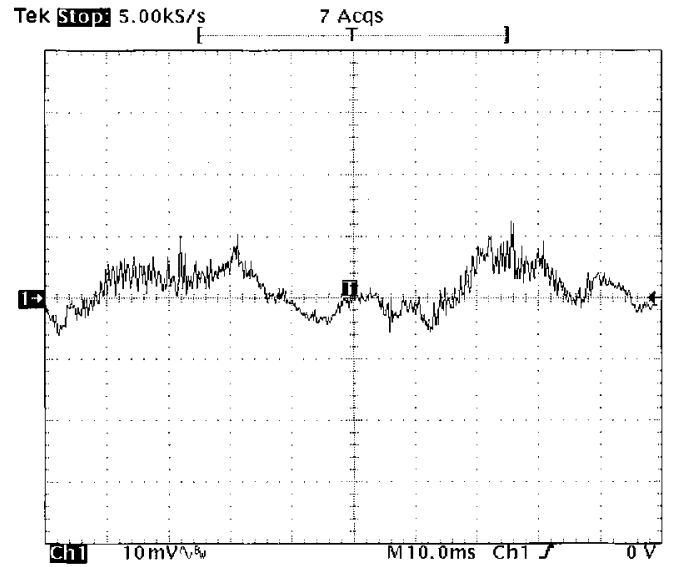

(a)

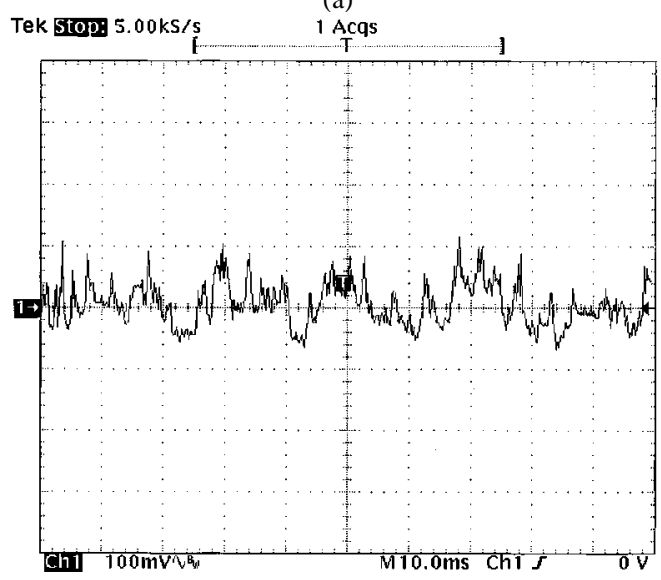

(c)

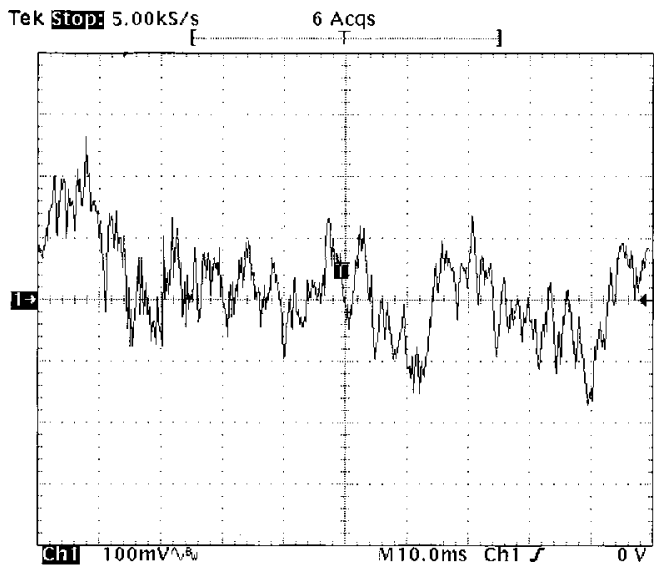

(b)

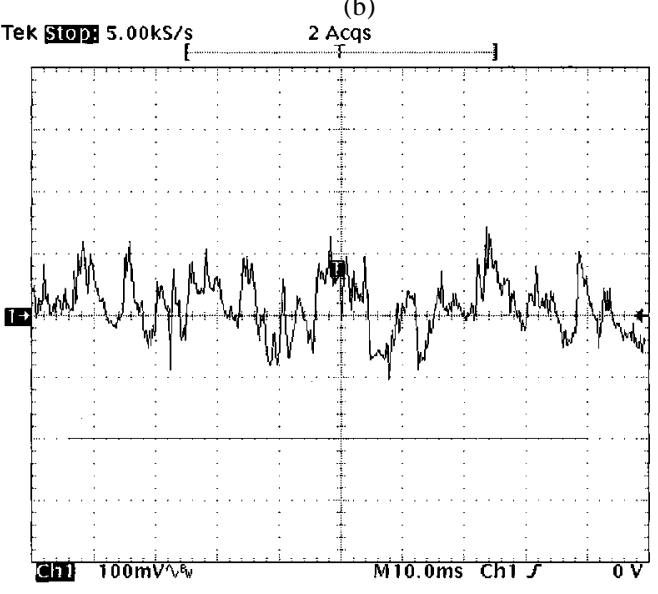

(d)

Fig. 8. Measured output noise ripples with different random switching schemes (time: $10 \mathrm{mV} / \mathrm{div}$ ). (a) RPPM (10 mV/div). (b) RPWM (100 mV/div). (c) RCFMFD (100 mV/div). (d) RCFMVD (100 mV/div).

where $B W_{\text {res }}$ is the resolution bandwidth of the spectrum analyzer and $S_{p}\left(f_{o}, \Re\right)$ is the actual PSD of $i_{\mathrm{in}}$, which is defined in (10). If $B W_{\text {res }}$ is narrow, the continuous spectrum of $S_{p \text {, measured }}\left(f_{o}, \Re\right)$ and $S_{p}\left(f_{o}, \Re\right)$ will be approximately the same. However, for the discrete harmonics, $S_{p}$, measured $\left(f_{o}, \Re\right)$ will be expressed as

$$
S_{p, \text { measured }}\left(f_{o}, \Re\right)=\frac{S_{p}\left(f_{o}, \Re\right)}{B W_{\text {res }}}
$$

Since $B W_{\text {res }}$ equals $100 \mathrm{~Hz}$, there is a $20-\mathrm{dB}$ difference between the theoretical value and the measured value at the discrete harmonics.

It can be observed that the spectrums of $i_{\text {in }}$ with RCFMFD and RCFMVD are continuous without discrete harmonics as occurred in RPPM and RPWM. Moreover, the peak harmonic component of $i_{\mathrm{in}}$ in RPPM and RPWM is $-12 \mathrm{dBm} / \mathrm{Hz}$, while the one in RCFMFD and RCFMVD is $-40 \mathrm{dBm} / \mathrm{Hz}$, showing that the latter two schemes are relatively effective in conducted EMI suppression. Fig. 6 shows the variations of the PSD of $i_{\text {in }}$ with respect to the variation in $\Re$ under the four random switching schemes, in which $\Re$ is changed from 0 to 0.2 . When $\Re=0$, the PSD is the same as the PSD of the classical PWM scheme. In general, the harmonic spectrum is gradually spread over as $\Re$ increases. Nevertheless, the PSD's of the RPPM and RPWM schemes consist of two components: a discrete component at the multiples of $f_{S}$ and a continuous component over the frequencies. The PSD's of the RCFMFD and RCFMVD only contain continuous spectrum. It is mainly due to the fact that the switching period in these two schemes is randomized.

The low-frequency characterizations of $v_{\text {out }}$ are shown in Fig. 7. It can be seen that. among the four schemes, RPWM gives the largest low-frequency ripple voltage on the converter output, while RPPM gives the smallest. This can be explained qualitatively by considering the energy transferred from the inductor to the output load in a considerable period of time, for example, in $1 \mathrm{~s}$. As the inductor energy is completely transferred to the output load in a switching cycle in DCM, the energy stored in a switching cycle is independent of the previous cycle. Hence, although the pulse position of RPPM is randomized in every switching cycle, the total energy transferred to the load in the considered period is unchanged. This gives the smallest low-frequency variation in the output voltage. For the same reason, RCFMVD gives slightly smaller low-frequency ripple voltage than the RCFMFD. It is because the duty time of the main switch in RCFMVD is relatively fixed. The energy transferred to the load is comparatively constant. For RPWM, the randomized duty time of the main switch causes significant variation in the output.

At the frequency range beyond the switching frequency $f_{S}$, RCFMFD gives the lowest magnitude in the harmonics. This phenomenon can be explained by considering the 
energy transferred from the inductor to the output load in every switching cycle. The duty cycle in RCFMFD in every switching cycle is constant even if the switching frequency is randomized, providing a relatively stable input-to-output conversion ratio. This factor can be observed from the behaviors of RPPM, RPWM and RCFMVD schemes, in which relatively large voltage variations are present because of the varying duty cycle. Although the average duty cycle in RPPM is constant, the actual ratio between the on time and off time of the main switch in every switching cycle is randomized. Thus, the magnitude of the high-frequency harmonics is higher than that of RCFMFD.

The magnitudes of $v_{N}$ under the four schemes are determined by using (35) and (36). With $N=2000, v_{N}$ was found to be $8.1 \mathrm{mV}$ in the RPPM scheme, $94.7 \mathrm{mV}$ in RPWM scheme, 24.7 $\mathrm{mV}$ in both the RCFMFD and RCFMVD schemes. Fig. 8 shows the experimental output ripple of the converter under the four switching schemes. The results show close agreement with the numerical predictions.

It has been reported previously that, when the converter is operated in CCM, RCFMFD offers the best spectral characteristics in dc/dc converter applications among the random schemes under consideration [11]. However, RPPM gives the smallest low-frequency ripple voltage in DCM. This gives a different observation in random switching technique for $\mathrm{dc} / \mathrm{dc}$ power conversion. Nevertheless, the advantage of small low-frequency noise in RPPM is offset by the existence of the discrete components at the multiples of the switching frequency and the ineffectiveness in spreading the spectrum of $i_{\text {in }}$ at the multiples of $f_{S}$, counteracting its usage in EMI suppression. Finally, comparing RCFMVD with RCFMFD, although the former technique gives a slightly smaller low-frequency noise ripple voltage, the latter one is still a good method for practical implementation in a PWM regulator. The gating signal can be obtained from a PWM modulator that compares the feedback control signal with a ramp voltage having randomized period, which is generated by a voltage-controlled oscillator.

\section{CONCLUSIONS}

This paper has given a comparative investigation into the effects of the randomness level on the PSD's of the four random modulation schemes that are applied to dc/dc converters operating in DCM. All schemes can gradually spread the discrete frequency component in the classical PWM scheme to a continuous frequency spectrum. However, continuous noise spectrum within the passband of the low-pass filter results in a noiseinduced low-frequency ripple in the converter output voltage. Among all schemes, although RPPM gives the lowest low-frequency ripple voltage, RCFMFD is still a good choice because of its effectiveness in conducted EMI suppression and of its ease in practical implementation.

\section{REFERENCES}

[1] F. Lin and D. Y. Chen, "Reduction of power supply EMI emission by switching frequency modulation," IEEE Trans. Power Electron., vol. 9, pp. 132-137, Jan. 1994.
[2] D. Stone and B. Chambers, "The effects of carrier frequency modulation of PWM waveforms on conducted EMC problems in switched mode power supplies," EPE J., vol. 5, no. 3/4, pp. 32-37, Jan. 1996.

[3] D. Middleton, An Introduction to Statistical Communication Theory. New York: IEEE Press, 1996.

[4] M. P. Kazmierkowski and F. Blaabjerb, "Impact of emerging technologies on PWM control of power electronic converters," IEEE Ind. Electron. Soc. Newslett., pp. 9-13, Dec. 1995.

[5] S. Cuk and R. D. Middlebrook, "A general unified approach to modeling switching dc-to-dc converters in discontinuous conduction mode," in Proc. IEEE PESC'77, 1977, pp. 36-57.

[6] H. Ott, Noise Reduction Techniques in Electronic Systems. New York: Wiley, 1989.

[7] A. M. Stankovic, G. C. Verghese, and D. J. Perreault, "Analysis and synthesis of randomised modulation schemes for power converters," IEEE Trans. Power Electron., vol. 10, pp. 680-693, Nov. 1995.

[8] T. Tanaka, K. Harada, and T. Ninomiya, "Noise analysis of dc-to-dc converter with random switching control," in Proc. INTELEC'91, Nov. 1991, pp. 283-290.

[9] T. Tanaka, T. Ninomiya, and K. Harada, "Random switching control in DC-DC converters," in Proc. IEEE PESC'89, 1989, pp. 500-507.

[10] A. Papoulis, Probability Random Variables, and Stochastic Processes. New York: McGraw-Hill, 1991.

[11] K. K. Tse, H. Chung, S. Y. R. Hui, and H. C. So, "A comparative investigation on the use of random modulation schemes for dc/dc converters," IEEE Trans. Ind. Electron., vol. 47, pp. 253-263, Apr. 2000.

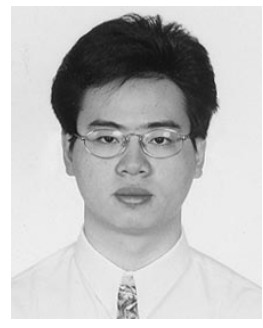

K. K. Tse (S'95-M'99) received the B.Eng. (Hons.) degree in electrical engineering from The Hong Kong Polytechnic University, Hong Kong, and the Ph.D. degree in electronic engineering from City University of Hong Kong, Hong Kong, in 1995 and 2000, respectively.

He is currently a Research Fellow in the Department of Electronic Engineering, City University of Hong Kong. His research interests include computeraided simulation techniques and EMI reduction using random switching schemes for dc-dc converters. He has authored 20 technical papers in his research areas.

Dr. Tse was awarded the First Prize in the 1998/1999 IEEE Postgraduate Student Paper Contest, Hong Kong Section, and the Third Prize in the 1998/1999 IEEE Postgraduate Student Paper Contest, Region 10. He was the recipient of the Croucher Foundation Fellowship in 2000.

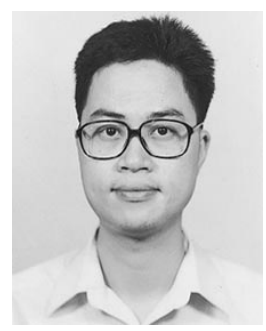

Henry Shu-hung Chung (S'92-M'95) received the B.Eng. degree (with first-class honors) in electrical engineering and the Ph.D. degree from The Hong Kong Polytechnic University, Hong Kong, in 1991 and 1994, respectively.

Since 1995, he has been with the City University of Hong Kong, Hong Kong, where he is currently an Associate Professor in the Department of Electronic Engineering. His research interests include time- and frequency-domain analysis of power electronic circuits, switched-capacitor-based converters, randomswitching techniques, digital audio amplifiers, and soft-switching converters. He has authored two research book chapters and more than 105 technical papers, including 47 refereed journal papers in his current research areas. He is currently Chairman of the Council of the Sir Edward Youde Scholar's Association.

Dr. Chung was the recipient of the China Light and Power Prize and was awarded the Scholarship and Fellowship of the Sir Edward Youde Memorial Fund in 1991 and 1993, respectively. He is currently the IEEE Student Branch Counselor at the City University of Hong Kong. He was Track Chair of the Technical Committee on Power Electronics Circuits and Power Systems of the IEEE Circuits and Systems Society in 1997-1998. He is presently an Associate Editor of the IEEE TRANSACTIONS ON CIRCUITS AND SYSTEMS-PART I: FUNDAMENTAL THEORY AND APPLICATIONS. He has also been listed in Marquis' Who's Who in the World. 


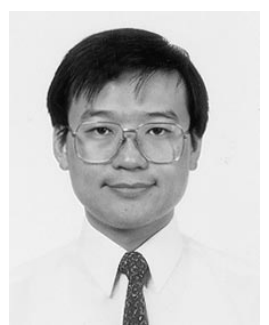

S. Y. (Ron) Hui (M'87-SM'94) was born in Hong Kong in 1961. He received the B.Sc (Hons.) degree in 1984 from the University of Birmingham, Birmingham, U.K., and the D.I.C. and Ph.D degree in 1987 from Imperial College of Science, Technology and Medicine, London, U.K.

$\mathrm{He}$ was a Lecturer in power electronics at the University of Nottingham, Nottingham, U.K., during 1987-1990. In 1990, he became a Lecturer at the University of Technology, Sydney, Australia, where he became a Senior Lecturer in 1991. He later joined the University of Sydney, Sydney, Australia, where he became a Reader of Electrical Engineering and Director of the Power Electronics and Drives Research Group in 1996. He is currently a Chair Professor of Electronic Engineering, City University of Hong Kong, Hong Kong. He has authored more than 140 published technical papers, including more than 70 refereed journal publications. His research interests include all aspects of power electronics.

Prof. Hui is a Fellow of the Institution of Electrical Engineers, U.K., The Instituion of Engineers, Australia, and Hong Kong Institution of Engineers. He is an Associate Editor of the IEEE TRANSACTIONS ON POWER ELECTRONICS. In 1999, he received the Teaching Excellence Award from the City University of Hong Kong.

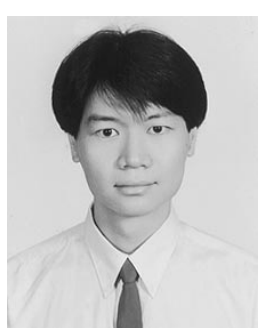

H. C. So (''90-M'90) was born in Hong Kong in 1968. He received the B.Eng. degree from City Polytechnic of Hong Kong, Hong Kong, and the Ph. D. degree from the Chinese University of Hong Kong, Hong Kong, in 1990 and 1995, respectively.

From 1990 to 1991, he was an Electronic Engineer in the Research and Development Division, Everex Systems Engineering Ltd. During 1995-1996, he was a Post-Doctoral Fellow at the Chinese University of Hong Kong. He is currently a Research Assistant Professor in the Department of Electronic Engineering, City University of Hong Kong, Hong Kong. His research interests include adaptive signal processing, detection and estimation, source localization, and wavelet transform. 